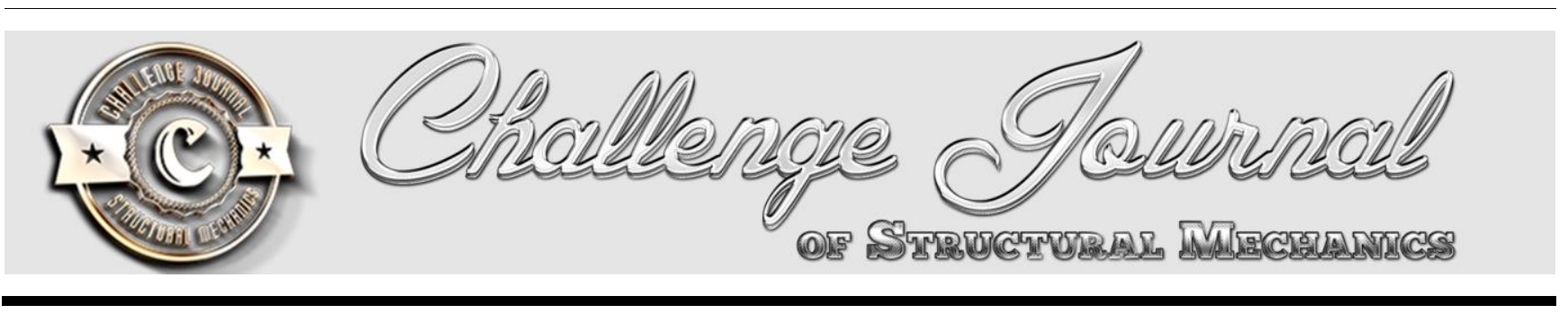

\title{
Defining parameters for concrete damage plasticity model
}

\author{
Yusuf Sümer*, Muharrem Aktaş \\ Department of Civil Engineering, Sakarya University, 54187 Sakarya, Turkey
}

\section{ABS T RAC T}

Behavior of reinforced concrete beam cannot be captured by elastic damage models or elastic-plastic constitutive laws only. When these two models coupled, load deflection behavior of reinforced concrete can be observed through numerical modeling. Thus, using concrete damage plasticity approach in finite element modeling can lead researches for sufficient numerical results when compared to experimental tests. In order to determine the material damage model of concrete, some laboratory tests are required. This paper offers an equation for damage parameter to capture damage behavior. In addition, modeling strategies are developed by checking the model sensitivity against mesh density, dilation angle and fracture energy of concrete. Finite element models are verified by three different experimental tests. In this study ABAQUS finite element software is employed to model reinforced concrete beam with concrete damage plasticity approach. This study shows that difference between the results from numerical models and experimental tests are in acceptable range.
\end{abstract}

\section{ARTICLE INFO}

Article history:

Received 14 May 2015

Accepted 11 July 2015

\section{Keywords:}

Finite element method

Reinforced concrete beam

Plastic damage model

Failure mechanisms

\section{Introduction}

Constitutive behavior of concrete is very difficult to capture by using elastic damage models or elastic plastic laws. In elastic damage model irreversible strains cannot be captured. It can be seen in Fig. 1(b) that a zero stress corresponds to a zero strain which makes damage value to be overestimated. On the other hand when elastic plastic relation is adopted the strain will be overestimated since the unloading curve will follow the elastic slope (Fig. 1(c)). Concrete Damage Plasticity (CDP) model which combines these two approaches can capture the constitutive behavior of experimental unloading (Fig. 1(a)) (Jason et al., 2004).

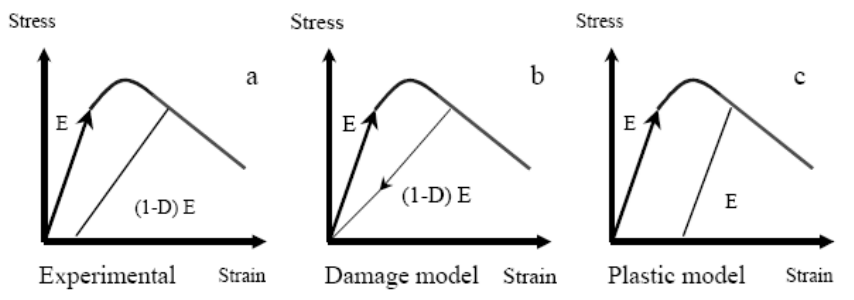

Fig. 1. Elastic plastic damage law (Jason et al., 2004).
In this model two main failure mechanisms are assumed: tensile cracking and compressive crushing of the concrete. The evolution of the yield surface is controlled by tensile and compressive equivalent plastic strains. In the following sections main assumptions about this model will be discussed in detail. In this study, developing a finite element model along with required parameters is discussed. ABAQUS nonlinear finite element commercial software package is employed. All the modeling parameters are validated by experimental results.

\section{Material Constitutive Behaviors}

Numerical models for the constituent material properties are described in this section.

\subsection{Concrete model}

CDP is one of the possible constitutive models to predict the constitutive behavior of concrete. It describes the constitutive behavior of concrete by introducing scalar damage variables. Tensile and compressive response of concrete can be characterized by CDP in Fig. 2.

* Corresponding author. Tel.: +90-264-2696908 ; Fax: +90-264-2956424 ; E-mail address: ysumer@sakarya.edu.tr (Y. Sümer) ISSN: 2149-8024 / DOI: http://dx.doi.org/10.20528/cjsmec.2015.07.023 

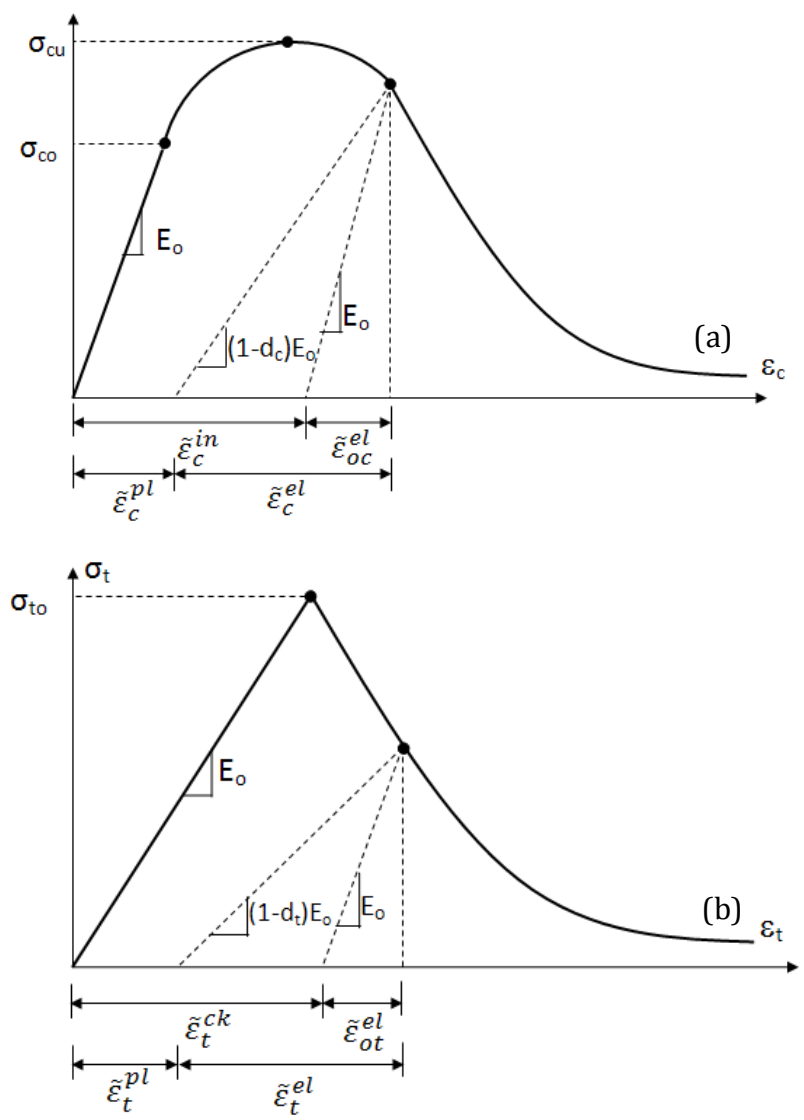

Fig. 2. Behavior of concrete under axial compressive (a) and tension(b) strength (Abaqus User Manual, 2008).

As shown in Fig. 2, the unloaded response of concrete specimen seems to be weakened because the elastic stiffness of the material appears to be damaged or degraded. The degradation of the elastic stiffness on the strain softening branch of the stress-strain curve is characterized by two damage variables, $d_{t}$ and $d_{c}$, which can take values from zero to one. Zero represents the undamaged material where one represents total loss of strength (Abaqus User Manual, 2008). $E_{0}$ is the initial (undamaged) elastic stiffness of the material and $\varepsilon_{c}^{\sim p l}, \varepsilon_{t}^{\sim p l}, \varepsilon_{c}^{\sim i n}, \varepsilon_{t}^{\sim i n}$ are compressive plastic strain, tensile plastic strain, compressive inelastic strain and tensile inelastic strain respectively. The stress-strain relations under uniaxial tension and compression are taken into account in Eq. (1) and Eq. (2).

$\sigma_{t}=\left(1-d_{t}\right) \cdot E_{0} \cdot\left(\varepsilon_{t}-\varepsilon_{t}^{\sim p l}\right)$,

$\sigma_{c}=\left(1-d_{c}\right) \cdot E_{0} \cdot\left(\varepsilon_{c}-\varepsilon_{c}^{\sim p l}\right)$.

Interface behavior between rebar and concrete is modeled by implementing tension stiffening in the concrete modeling to simulate load transfer across the cracks through the rebar. Tension stiffening also allows to model strain- softening behavior for cracked concrete. Thus it is necessary to define Tension stiffening in CDP model. ABAQUS allows us to specify Tension Stiffening by post failure stress-strain relation or by applying a fracture energy cracking criterion (Abaqus User Manual, 2008).
There is a mesh sensitivity problem when cracking failure in not distributed evenly. This phenomenon exists when there is no reinforcement in significant regions of the model. To overcome this unreasonable mesh sensitivity problem Hillerborg's (1976) fracture energy approach can be used instead of post failure stress-strain relation (Hillerborg et al., 1976). In this approach; the amount of energy $\left(G_{F}\right)$ which is required to open a unit area of crack is assumed as a material property. Thus; concrete's brittle behavior is defined by stress-displacement response rather than a stress-strain response. Specifying the post failure stress versus corresponding cracking displacement is enough to describe this approach as shown in Fig. 3(a-b) (Abaqus User Manual, 2008).
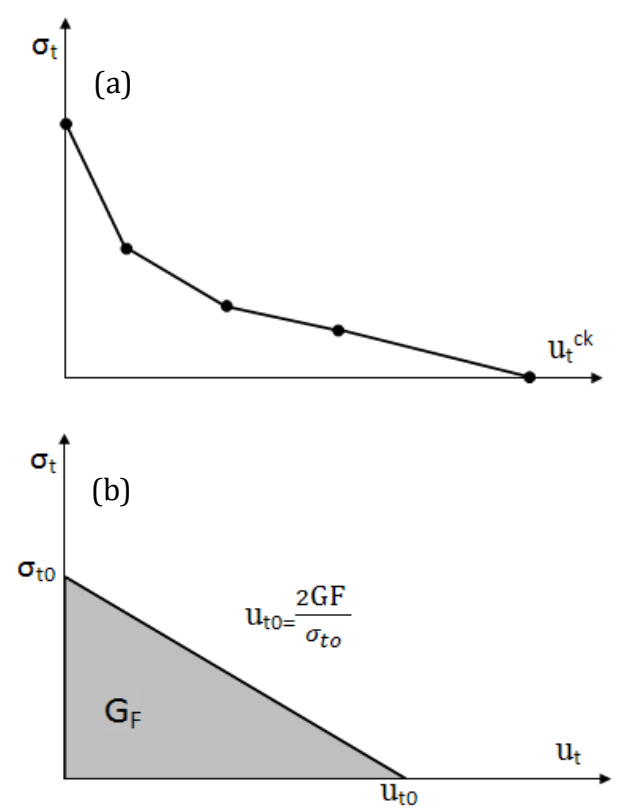

Fig. 3. Post failure stress-strain relation with fracture energy approach (Abaqus User Manual, 2008).

As an alternative, $G_{F}$ can be implemented directly as a material property. However in this case, a linear loss of strength after cracking is assumed (Fig. 3(b)). From CDP perspective, ABAQUS automatically calculates both plastic displacement values using the Eq. (3) and Eq. (4).

$u_{t}^{p l}=u_{t}^{c k}-\frac{d_{t}}{\left(1-d_{t}\right)} \frac{\sigma_{t} I_{0}}{E_{0}}$

$\varepsilon_{c}^{\sim p l}=\varepsilon_{c}^{\sim i n}-\frac{d_{c}}{\left(1-d_{c}\right)} \frac{\sigma_{c}}{E_{0}}$.

From these equations "effective" tensile and compressive cohesion stresses $\left(\bar{\sigma}_{t}, \bar{\sigma}_{c}\right)$ can be defined as:

$\bar{\sigma}_{t}=\frac{\sigma_{t}}{\left(1-d_{t}\right)}=E_{0}\left(u_{t}-u_{t}^{p l}\right)$

$\bar{\sigma}_{c}=\frac{\sigma_{c}}{\left(1-d_{c}\right)}=E_{0}\left(\varepsilon_{c}-\varepsilon_{c}^{\sim p l}\right)$.

The effective cohesion stresses determines the size of the yield (or failure) surface (see Fig. 4). In Abaqus the parameters required to define the yield surface consists 
of four constitutive parameters. The Poisson's ratio controls the volume changes of concrete for stresses below the critical value which is the onset of inelastic behavior. Once the critical stress value is reached concrete exhibits an increase in plastic volume under pressure (Chen, 1982). This behavior is taken into account by defining a parameter called the angle of dilation. In CDP model $\psi$ is the dilation angle measured in the $\mathrm{p}-\mathrm{q}$ plane at high confining pressure and in this study it is determined with sensitivity analysis. $\epsilon$ is an eccentricity of the plastic potential surface with default value of 0.1 . The ratio of initial biaxial compressive yield stress to initial uniaxial compressive yield stress, $\sigma_{b 0} / \sigma_{c 0}$, with default value of 1.16. Finally $K_{c}$ is the ratio of the second stress invariant on the tensile meridian to compressive meridian at initial yield with default value of 2/3 (Abaqus User Manual, 2008). The parameter $K_{c}$ should be defined based on the full triaxial tests of concrete, moreover biaxial laboratory test is necessary to define the value of $\sigma_{b 0} / \sigma_{c 0}$. This paper does not discuss the identification procedure for parameters $\epsilon, \sigma_{b 0} / \sigma_{c 0}$, and $\mathrm{K}_{c}$ because tests that are going to be verified in this study do not have such information. Thus, default values are accepted in this study.

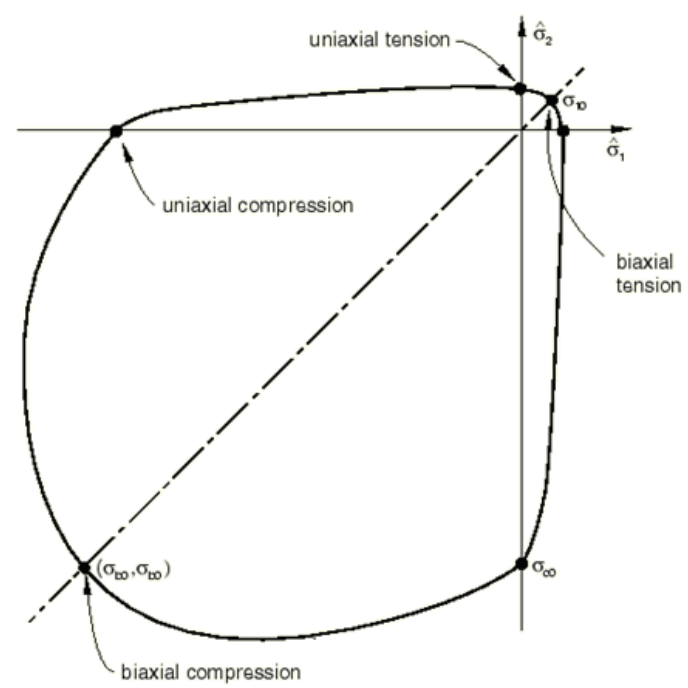

Fig. 4. Biaxial yield surface in CDP Model (Abaqus User Manual, 2008).

\subsubsection{Uniaxial tension and compression stress behavior of test model}

Since the compression and tension stress behavior of the experimental test specimens are not reported these relations are created by using mathematical models from literature. The compressive behavior of concrete is obtained by employing Hognestad probala along with linear descending branch. However the crushing of concrete is affected by the closed stirrups and some modifications are made for concrete in compression according to CEB-FIP MC90 (Fig. 5(a)) (CEB-FIB, 1993). Equation of the parabola is shown in Eq. (7) where $\sigma$ is the compressive stress, $f_{c u}$ is ultimate compressive stress, $\varepsilon_{c}{ }^{*}$ is the peak compressive strain, $E$ is the elastic modulus and $f_{c}{ }^{*}$ is the modified compressive strength. Details of this model can be found in Arduini et al., 1997.

$$
\sigma=f_{c}^{*}\left(\frac{2 \varepsilon}{\varepsilon}-\left[\frac{\varepsilon}{\varepsilon_{c}^{*}}\right]^{2}\right)
$$
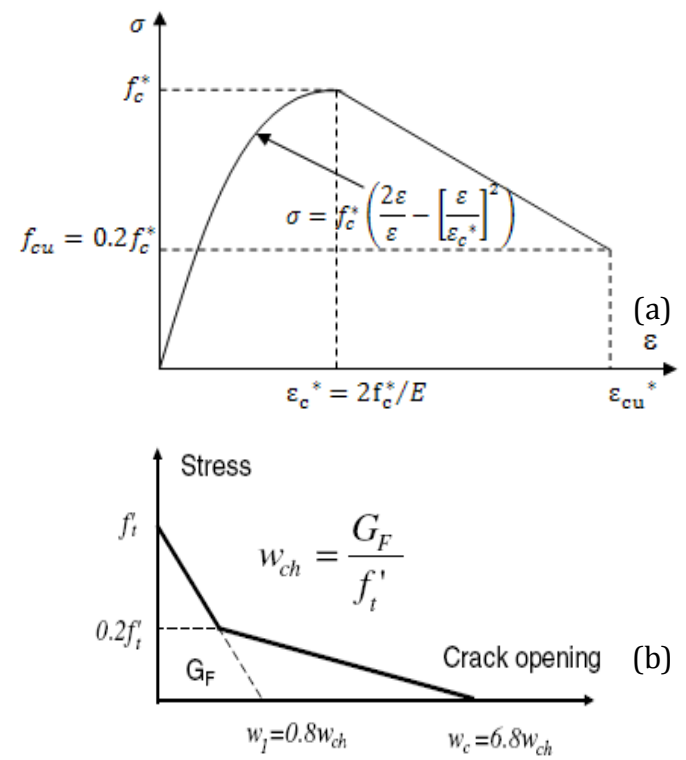

(b)

Fig. 5. Stress-strain behavior of concrete under uniaxial compression and tension a) Hognestad concrete compressive behavior b) Bilinear tensile behavior.

For tensile behavior of concrete, bilinear model is adopted as plotted in Fig. 5(b) (Coronado and Lopez, 2006). Crack opening ( $\left.w_{c}\right)$ is calculated as a ratio of the total external energy supply $\left(G_{F}\right)$ per unit area required to create, propagate and fully break a Mode I crack in concrete. However; Mode I tensile fracture energy of concrete is defined as a function of the concrete compressive strength, $f_{c}{ }^{*}$, in CEB-FIP MC90 (CEB-FIB, 1993) as shown in Eq. (8). In this equation $G_{f o}$ is a coefficient related to the maximum aggregate size $\left(d_{\max }\right)$. Several values are given in Table 1.

$G_{F}=G_{f o}\left(\frac{f_{c}^{*}}{10}\right)^{0.7}$

Table 1. Aggregate size-based fracture coefficients (Rots, 1988).

\begin{tabular}{cc}
\hline $\begin{array}{c}\text { Maximum aggregate size } \\
d_{\max }(\mathrm{mm})\end{array}$ & $\begin{array}{c}\text { Coefficient } \\
G_{f o}\left(\mathrm{~J} / \mathrm{m}^{2}\right)\end{array}$ \\
\hline 8 & 25 \\
16 & 30 \\
32 & 58 \\
\hline
\end{tabular}

Thus, uniaxial tension and compression stress behavior are defined by using above mathematical models. These mathematical models are not enough to define CDP model. As mentioned above damage parameters are required to specify the CDP model. But these damage parameters are not reported for the experiments that are going to be verified in this study. Most of the reinforced concrete flexural test reports in the literature are also 
missing this information. Because to define these damage parameters, some laboratory tests in material level should be done in advance. In this study damage parameter for concrete compressive behavior is obtained from a verification problem given in ABAQUS verification manual. By applying curve fitting method to this example a third degree polynomial curve as in Eq. (9) is obtained for this corresponding damage parameter (Fig. 6(a)). Then the very same equation is applied to get the damage parameter for the test cases that are going to be verified in this study. Also tension damage parameter is obtained by following the same behavior of example material given in ABAQUS verification manual (Fig. 6(b)).

$y=2 E+0.6 x^{3}-41740 x^{2}+324 . x+0.0052$.
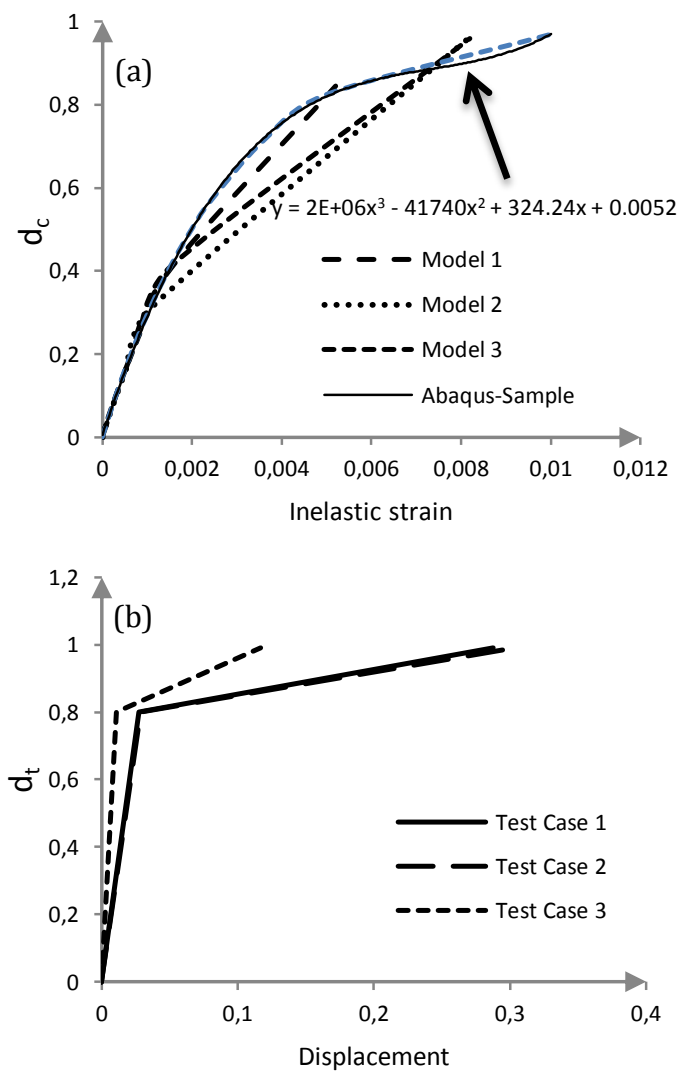

Fig. 6. Compression and tension damage parameters used in the models a) Compression damage parameter b) Tension damage parameter.

\subsection{Uniaxial tension behavior of steel}

The stress-strain curve of the reinforcing bar is assumed to be elastic perfectly plastic as shown in Fig. 7. In this model material yields under constant load. The parameters needed to specify this behavior are the modulus of elasticity $\left(E_{s}\right)$, poisson ratio $(v)$ and yield stress $\left(f_{y}\right)$.

\section{Verification Test Group}

Developing the finite element model strategies for reinforced concrete beam is verified by the experiment studies. A total of 3 beams with different mechanical properties from different researchers, were selected for verification purpose. All the beams are tested under four point load. Test layout and material properties for each experiment are given in Figure 8 and Table 2. All the details of Test Case 1, Test Case 2, and Test Case 3 can be found in Arduini et al. (1997), Benjeddou et al. (2007) and Sharif et al. (1994) respectively.

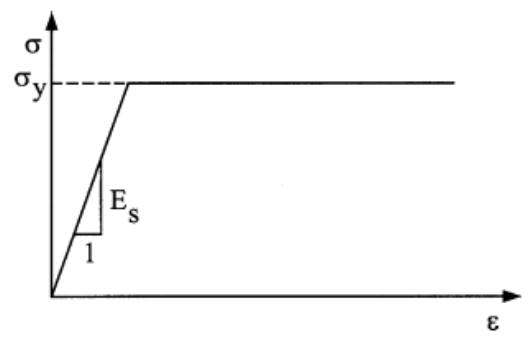

Fig. 7. Elastic perfectly plastic model for steel reinforcing bars.

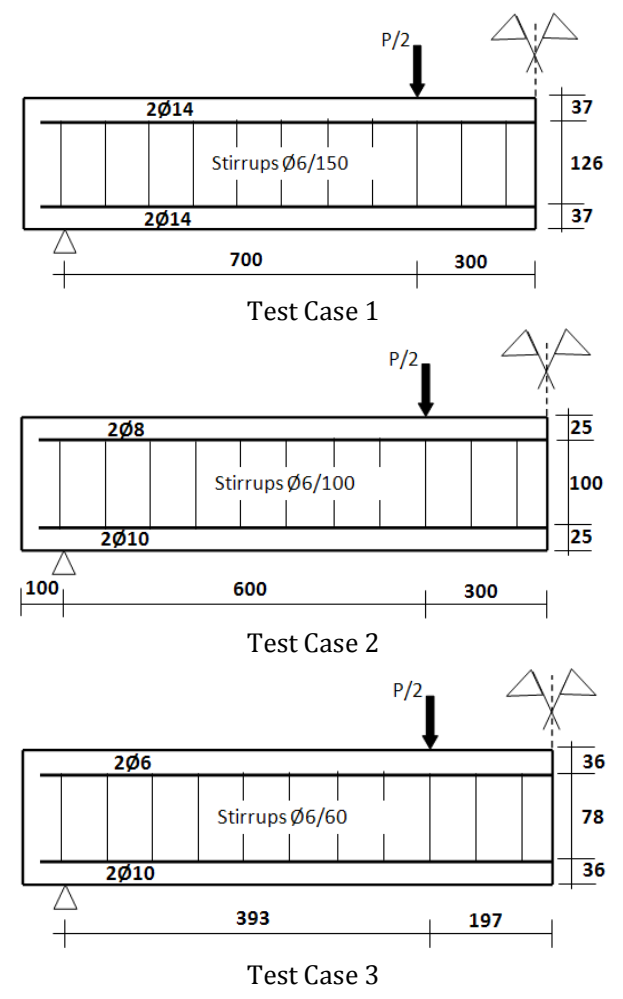

Fig. 8. Layout of test beam (dimensions are mm).

\section{Finite Element Modeling}

The non-linear finite element software package, ABAQUS, is employed for numerical analysis. Since there is no computational expense all the beams are modeled with full geometry in 2 dimensions (Fig. 9). Steel bars are embedded in concrete with the same degrees of freedom which also means that there is a perfect bond between concrete and steel. The advantage of the embedded model is that it allows independent choice of the concrete mesh. Concrete is modeled by using four-noded plain strain element with reduced integration formulation. Since first order elements use linear interpolation to obtain nodal displacements, the edges of these elements are unable to curve under bending resulting in 
shear rather than bending deformation. This phenomenon is known as shear locking (Abaqus User Manual, 2008). To overcome this problem element with reduced integration formula is employed. All the beams are loaded by displacement control in the vertical direction. Finite element members and typical finite element mesh geometry employed in this study can be seen in Table 3 and Fig. 9.

Table 2. Material properties of test beams.

\begin{tabular}{ccccccccc}
\hline $\begin{array}{c}\text { Test } \\
\text { Case }\end{array}$ & $\begin{array}{c}\text { Beam } \\
\text { Ref. No }\end{array}$ & $\begin{array}{c}\text { Width, Height, Shear } \\
\text { span }(\mathrm{mm})\end{array}$ & $\begin{array}{c}E \\
(\mathrm{GPa})\end{array}$ & $\begin{array}{c}v \\
(-)\end{array}$ & $\begin{array}{c}f_{c}^{\prime} \\
(\mathrm{MPa})\end{array}$ & $\begin{array}{c}f_{y} \text { (Rebar) } \\
(\mathrm{MPa})\end{array}$ & $\begin{array}{c}f_{t} \\
(\mathrm{MPa})\end{array}$ & $\begin{array}{c}d_{\max } \\
(\mathrm{mm})\end{array}$ \\
\hline 1 & A1 & $200-200-2000$ & 25 & 0.2 & 33 & 400 & 2.6 & - \\
2 & CB1 & $120-150-1800$ & 30 & - & 21 & 400 & 1.8 & 16 \\
3 & P1 & $150-150-1180$ & 27 & - & 37.7 & 450 & - & - \\
\hline
\end{tabular}

Table 3. Finite element types.

\begin{tabular}{cccc}
\hline Material & Description & Code & Additional information \\
\hline Concrete & Four-noded plain strain & CPE4R & Reduced integration \\
Steel & Two-noded truss & T2D2 & Embedded \\
\hline
\end{tabular}

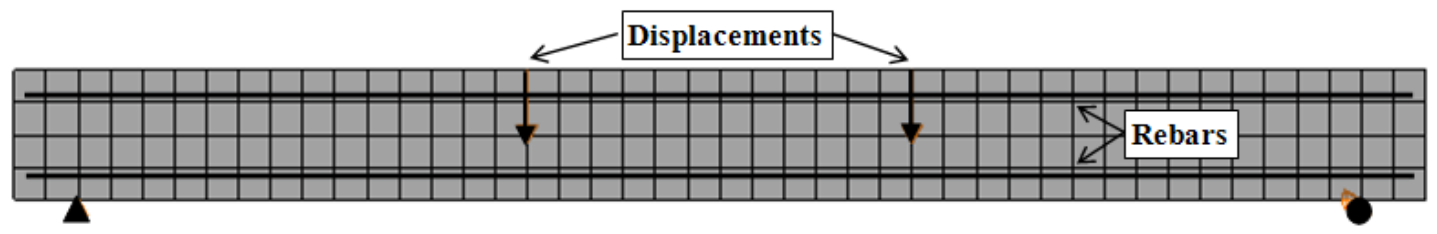

Fig. 9. Typical finite element mesh of numerical models.

\section{Results and Discussions}

\subsection{Test Case 1 (Arduini et al., 1997)}

It is clear that, the finite element simulation is very capable of capturing the experimentally observed loading trends and magnitudes for the entire loading range. For this test case, models with finer mesh captures the test result better than the models with course mesh (Fig. 10(a)). The best result is obtained with $50 \mathrm{~mm}$ mesh. The value for dilation angle for reinforced concrete in literature is given as $30^{\circ}$ (Lubliner et al., 1989). Based on this information angle of dilation is varied to see the sensitivity of the results against it. Plots show that the results are not varying dramatically as the dilation angle changes (Fig. $10(\mathrm{~b})$ ). The best result is observed at $37^{\circ}$. As discussed before $G_{F}$ depends on the diameter of aggregate (Eq. (8)). Since the aggregate diameter is not reported in test report this value is also changed to see how it affects the results. With the best results obtained from both mesh sensitivity and the dilation angle analysis, $G_{F}$ is calculated for different aggregate diameter and result are plotted in Fig. 10(c).

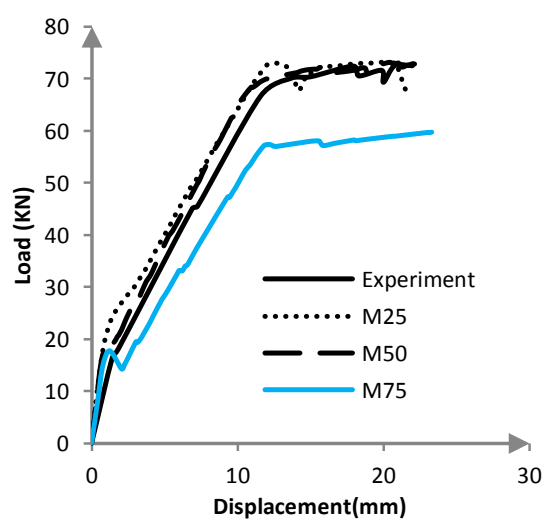

a) Mesh sensitivity

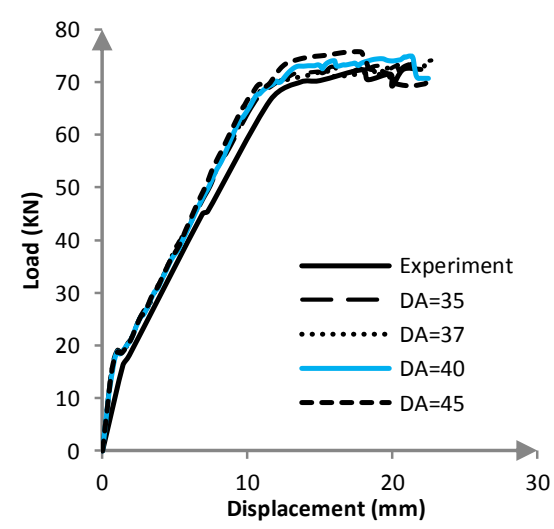

b) Dilation angle sensitivity

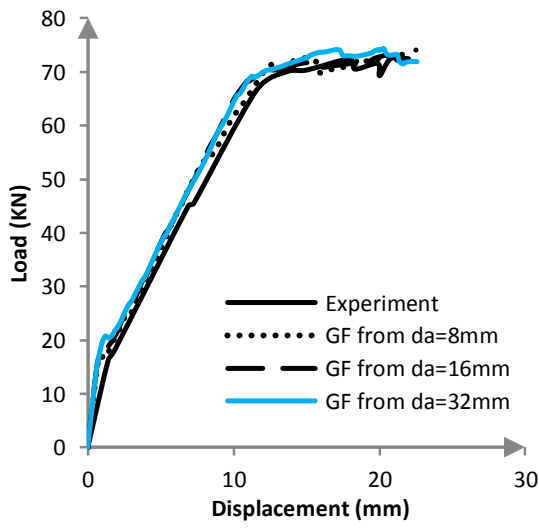

c) Fracture energy sensitivity

Fig. 10. Numerical results for Test Case 1. 


\subsection{Test Case 2 (Benjeddou et al., 2007)}

Similar results are also observed in this test case. However; models with finer mesh has more rigid behavior than models with course mesh. But still the difference is in the acceptable range. Also $50 \mathrm{~mm}$ mesh gives the best results as in Test Case 1 (Fig. 11(a)). Since it is found that the models are not dilation angle sensitive, in this model values for dilation angles are changed into $30^{\circ}$ and $50^{\circ}$ to seek for further different values. But still it is found that the behavior can be captured within the range of the dilation angle value reported in the literature (Fig. 11(b)). Also it is clear from this test case that modeling is not very sensitive to $G_{F}$ value (Fig. 11(c)).

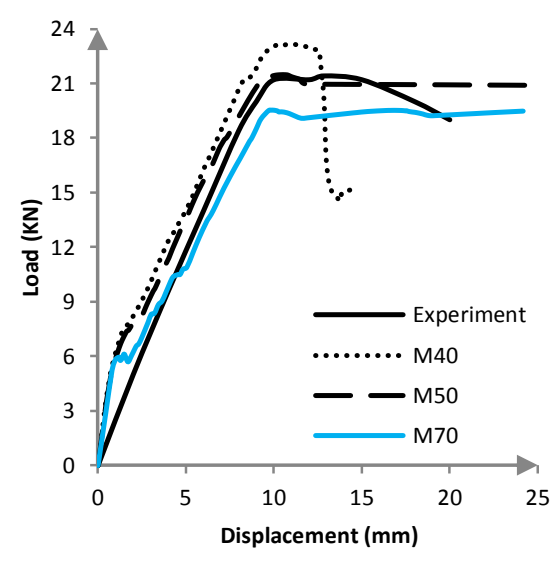

a) Mesh sensitivity

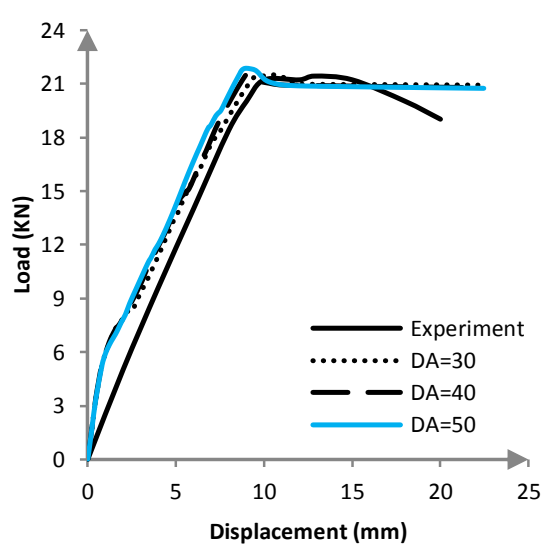

b) Dilation angle sensitivity

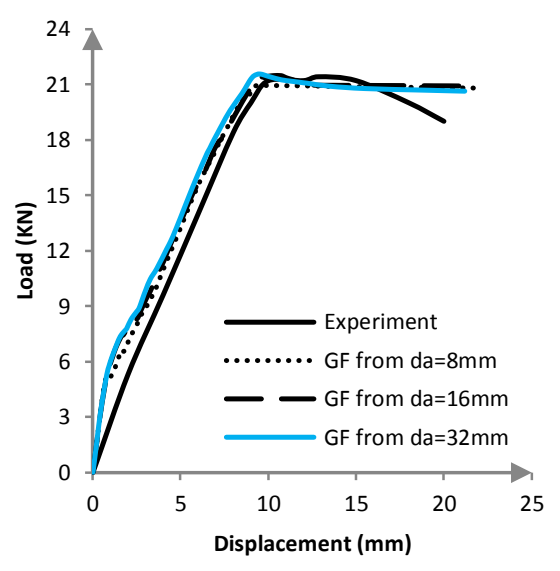

c) Fracture energy sensitivity

Fig. 11. Numerical results for Test Case 2.

\subsection{Test Case 3 (Sharif et al., 1994)}

This test case gives different results from other test cases. In this model some of the material properties are not reported in the test report. For example; $f_{t}$ value is not reported in the test report. $f_{t}$ value is calculated according to ACI (ACI 318, 1999). Unreported critical values such as elastic modulus, $f_{c}$ and $f_{t}$ change the results dramatically. But still the finite element simulation is capable of capturing the loading trends. In this case mesh with $25 \mathrm{~mm}$ captures the results of the experiment (Fig. 12(a)). But mesh with $50 \mathrm{~mm}$ model gives unrealistic results. Authors think that this is much related to the unreported diameter value of aggregate. Because in this case, the results are also very sensitive to $G_{F}$ unlike other cases (Fig. 12(c)). The mesh should be selected with a dimension that should include the continuum properties of the material. Dilation angle of $30^{\circ}$ captures the best results in this test case (Fig. 12(b)).

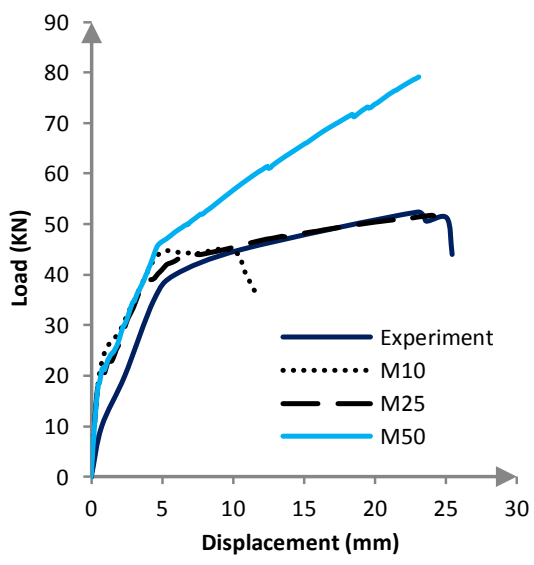

a) Mesh sensitivity

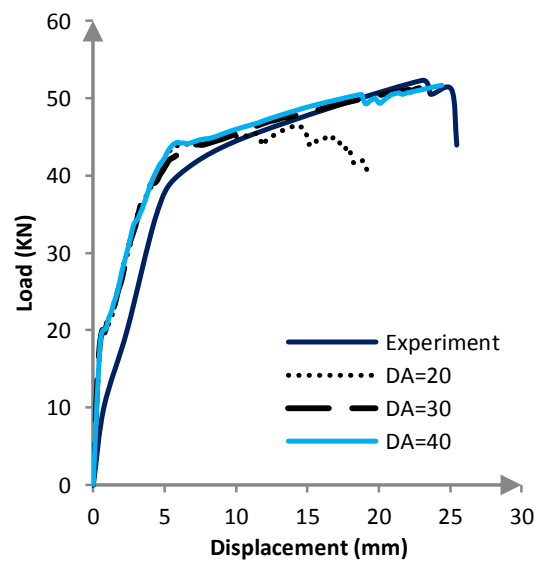

b) Dilation angle sensitivity

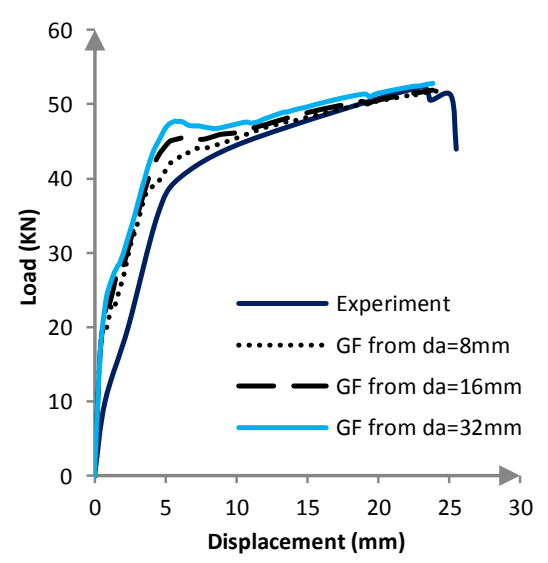

c) Fracture energy sensitivity

Fig. 12. Numerical results for Test Case 3.

Table 4 compares the experimental yield loads and deflections with those obtained from the finite element analysis for three test cases. As can be seen in Table 4, the predicted yield load and deflections for Test Case 1 and Test Case 2 is nearly same with experimental results.
However, yield load is $\% 7$ higher than experimental result for the Test Case 3. According to these results, proposed finite-element model proves its capability to accurately predict the load-deflection relationships of the reinforced concrete beams. 
Table 4. Comparison of results.

\begin{tabular}{|c|c|c|c|c|c|c|}
\hline & \multicolumn{2}{|c|}{ Test Case 1} & \multicolumn{2}{|c|}{ Test Case 2} & \multicolumn{2}{|c|}{ Test Case 3} \\
\hline & $\begin{array}{l}\text { Yield Load } \\
\qquad(\mathrm{kN})\end{array}$ & $\begin{array}{l}\text { Deflection } \\
\text { (mm) }\end{array}$ & $\begin{array}{l}\text { Yield Load } \\
\qquad(\mathrm{kN})\end{array}$ & $\begin{array}{l}\text { Deflection } \\
(\mathrm{mm})\end{array}$ & $\begin{array}{l}\text { Yield Load } \\
\qquad(\mathrm{kN})\end{array}$ & $\begin{array}{l}\text { Deflection } \\
(\mathrm{mm})\end{array}$ \\
\hline Experiment & 70 & 13.65 & 21.2 & 10 & 40 & 5.93 \\
\hline Finite Element & 70.9 & 13.64 & 21.4 & 9.4 & 42.8 & 5.95 \\
\hline Numeric/Experiment & 1.01 & 1.00 & 1.00 & 0.94 & 1.07 & 1.00 \\
\hline
\end{tabular}

\section{Conclusions}

Three different experimental tests are verified by using modeling strategies explained in the previous sections. Results show that experimentally observed loading trends and magnitudes for entire loading range of RC beams can be captured by employing CDP modeling approach. Basically mesh density, dilation angle and concrete fracture energy are calibrated to develop modeling strategies. It is obvious that if material properties and geometrical information about real test are given in detail then numerical models give better results than those with missing information. Also this study proves that defining damage parameters for compression behavior with proposed equation gives satisfactory results. But this equation can be improved with real test results for further investigations.

\section{REFERENCES}

ABAQUS (2008). User's Manual, Version 6.8, Hibbitt, Karlsson\&Sorensen, Inc., Pawtucket, Rhode Island, USA.

ACI 318-99 (1999). Building Code Requirements for Structural Concrete and Commentary. American Concrete Institute, Detroit, MI.
Arduini M, Di Tommaso A, Nanni A (1997). Brittle failure in FRP plate and sheet bonded beams. ACI Structural Journal, 94 (4), 363-70.

Benjeddou 0, Ouezdou BM, Bedday A (2007). Damaged RC beams repaired by bonding of CFRP laminates. Construction and Building Materials, 21(6), 1301-1310.

Chen WF (1982). Plasticity in Reinforced Concrete, XV. New York: McGraw-Hill, 474.

Comite Euro-International du Beton (1993). CEB-FIP Model Code 1990 (CEB-FIP MC90). Bulletin D'Information, No. 215, Lausanne.

Coronado CA, Lopez MM (2006). Sensitivity analysis of reinforced concrete beams strengthened with FRP laminates. Cement and Concrete Composites, 28(1), 102-114.

Hillerborg A, Modeer M, Petersson PE (1976). Analysis of crack formation and crack growth in concrete by means of fracture mechanics and finite elements. Cement and Concrete Research, 6, 773-782.

Jason L, Pijaudier-Cabot G, Huerta A, Ghavamian S (2004). Damage and plasticity for concrete behavior. European Congress on Computational Methods in Applied Sciences and Engineering, Jyväskylä.

Lubliner J, Oliver J, Oller S, Onate E (1989). Plastic-damage model for concrete. International Journal of Solids Structures, 25(3), 299-326.

Rots JG (1988). Computational Modeling of Concrete Fracture. Ph.D. thesis, Delft University of Technology, Delft, Netherlands.

Sharif A, Al-Sulaimani GJ, Basunbul IA, Baluch MH, Ghaleb BN (1994). Strengthening of initially loaded reinforced concrete beams using FRP plates. ACI Structural Journal, 91(2), 160-16. 